ARTICLE

DOI: $10.1038 / s 41467-018-04636-4$

\title{
Solvent-controlled growth of inorganic perovskite films in dry environment for efficient and stable solar cells
}

Pengyang Wang ${ }^{1,2}$, Xingwang Zhang 1,2, Yuqin Zhou ${ }^{2}$, Qi Jiang1,2, Qiufeng Ye ${ }^{1,2}$, Zema Chu' ${ }^{1}$ Xingxing $\mathrm{Li}^{1,2}$, Xiaolei Yang ${ }^{1}$, Zhigang Yin ${ }^{1,2} \&$ Jingbi You (1) ${ }^{1,2}$

Inorganic halide perovskites such as cesium lead halide are promising due to their excellent thermal stability. Cesium lead iodide $\left(\mathrm{CsPb}_{3}\right)$ has a bandgap of $1.73 \mathrm{eV}$ and is very suitable for making efficient tandem solar cells, either with low-bandgap perovskite or silicon. However, the phase instability of $\mathrm{CsPb}_{3}$ is hindering the further optimization of device performance. Here, we show that high quality and stable $\alpha$-phase $\mathrm{CsPbl}_{3}$ film is obtained via solvent-controlled growth of the precursor film in a dry environment. A $15.7 \%$ power conversion efficiency of $\mathrm{CsPbl}_{3}$ solar cells is achieved, which is the highest efficiency reported for inorganic perovskite solar cells up to now. And more importantly, the devices can tolerate continuous light soaking for more than $500 \mathrm{~h}$ without efficiency drop.

\footnotetext{
${ }^{1}$ Key Laboratory of Semiconductor Materials Science, Institute of Semiconductors, Chinese Academy of Sciences, Beijing 100083, China. ${ }^{2}$ College of Materials Science and Opto-electronic Technology, University of Chinese Academy of Sciences, Beijing 100049, China. Correspondence and requests for materials should be addressed to J.Y. (email: jyou@semi.ac.cn)
} 
alide perovskite semiconductors used in photovoltaic devices were reported by Miyasaka et al. in 2009. The power conversion efficiency (PCE) has increased rapidly to more than $20 \%$ in the past several years ${ }^{1-14}$. And the large area module of perovskite solar cells was also demonstrated recently ${ }^{15}$. Traditional perovskite solar cells were mainly based on organic-inorganic hybrid materials such as methylammonium lead halide $\left(\mathrm{MAPbX}_{3}, \mathrm{X}=\mathrm{Cl}, \mathrm{Br}, \mathrm{I}\right)$ and formamidinium lead halide $\left(\mathrm{FAPbX}_{3}, \mathrm{X}=\mathrm{Cl}, \mathrm{Br}, \mathrm{I}\right)$, or their mixture ${ }^{1-14}$. In addition to humidity instability, the organic-inorganic hybrid perovskite materials also suffer from poor thermal stability due to easy evaporation of the organic parts ${ }^{16,17}$.

Inorganic halide perovskite $\left(\mathrm{CsPb}_{3}\right)(\mathrm{X}=\mathrm{Cl}, \mathrm{Br}, \mathrm{I})$ could be more thermally stable, it was found that $\mathrm{CsPbX}_{3}$ can sustain temperatures exceeding $400{ }^{\circ} \mathrm{C}$ without any phase degradation ${ }^{18,19}$. This could be the reason of the significant photostability improvement of perovskite solar cells, while incorporating inorganic metal cations such as $\mathrm{Cs}$ or $\mathrm{Rb}$ into the organic cations in $\mathrm{MAPbI}_{3}$ or $\mathrm{FAPbI}_{3}$ perovskites ${ }^{11,} 20-23$. In addition to the excellent thermal stability, inorganic perovskite such as $\mathrm{CsPbI}_{3}$ showed an optical bandgap of $1.73 \mathrm{eV}^{24,25}$, which is an ideal material to configure tandem cells combined with either silicon or low-bandgap perovskite ${ }^{26-30}$. Even though similar bandgap could also be obtained from organic/inorganic perovskite by mixture halide strategy, halide segregation could be a critical issue for affecting photostability of the devices, while the halide dopant is more than $30 \%$ (such as $\left.\mathrm{FAPbI}_{0.6} \mathrm{Br}_{0.4}\right)^{27}$. Therefore, it is very meaningful to achieve high efficiency and stable $\mathrm{CsPbI}_{3}$ solar cells. However, it was found that the a-phase (black phase) of $\mathrm{CsPbI}_{3}$ could be rapidly degraded to nonphotoactive $\delta$-phase (yellow phase) in an ambient environment with moisture $25,31-35$. It has been explained that the moisture can effectively introduce vacancies in the crystal lattice and lower the free-energy barrier to nucleation, and trigger the phase transition of $\mathrm{CsPbI}_{3}$ perovskite even at room temperature ${ }^{32,33}$.

Previously, there are several efforts to stabilize the $\alpha$-phase of $\mathrm{CsPbI}_{3}$ to make efficient solar cells ${ }^{25,34-42}$, such as tuning the tolerance factor of perovskite structure by partially substituting iodide with bromide to form $\mathrm{CsPbI}_{2} \mathrm{Br}$ or $\mathrm{CsPbIBr}_{2}{ }^{34-37}$, reducing the crystal size $\mathrm{e}^{25}, 40,42$, or introducing intermediate phase such as $\mathrm{Cs}_{4} \mathrm{PbI}_{6}{ }^{41}$. All these efforts push the efficiency of inorganic perovskite solar cells to around $10 \%$. Recently, during the preparation of this manuscript, significant progresses were witnessed, around $13 \% \mathrm{PCE}$ of $\mathrm{CsPbI}_{3}$-based solar cells were reported by either doping $\mathrm{B}$ site in $\mathrm{ABX}_{3}$ perovskite structure ${ }^{43}$ or by passivating/stabilizing $\mathrm{CsPbI}_{3}$ quantum dot colloid via organic salt molecular ${ }^{44,45}$. Even though, there is still a large room for further improving the PCE of $\mathrm{CsPbI}_{3}$ solar cells. To deliver higher efficiency of $\mathrm{CsPbI}_{3}$-based perovskite solar cells, two issues must be resolved. One is forming stable $\alpha$-phase of $\mathrm{CsPbI}_{3} \mathrm{films}^{34}$. Another one is obtaining the high quality of $\mathrm{CsPbI}_{3}$ layer, similar to the initial development of organic-inorganic perovskite solar a

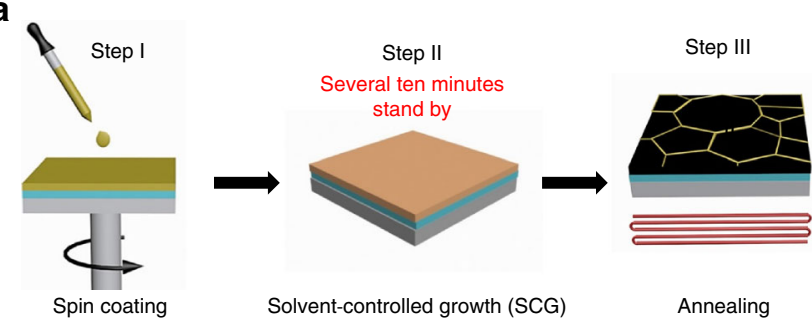

b



d

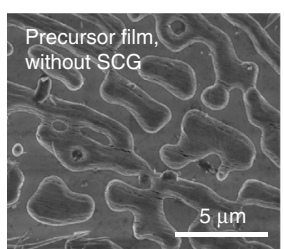

e



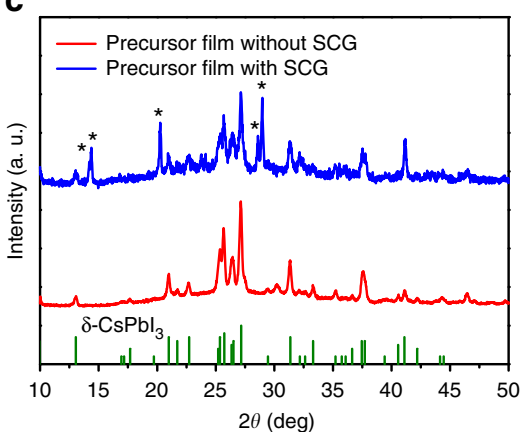

f

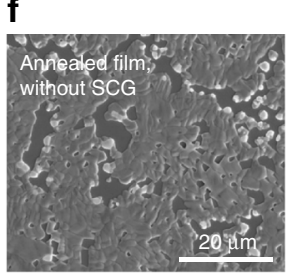

g



Fig. 1 Solvent-controlled growth (SCG) for $\mathrm{CsPbl}_{3}$ deposition. a Schematic illustration of $\mathrm{CsPb}_{3}$-perovskite crystallization procedures via solvent-controlled growth (SCG). b Normalized absorption of $\mathrm{CsPbl}_{3}$-precursor films with and without SCG, inset shows the precursor film images without and with SCG. c X-ray diffraction (XRD) pattern of $\mathrm{CsPb}_{3}$-precursor films without and with solvent-controlled growth (SCG). Without SCG, the diffraction peaks are mainly from the $\delta$-phase $\mathrm{CsPb}_{3}$, while after $\mathrm{SCG}$, part of $\delta$ - phase $\mathrm{CsPb}_{3}$ was transferred into $\beta$-phase $\mathrm{CsPb}_{3}$ (a slight distorted $\alpha$-phase $\mathrm{CsPb}{ }_{3}$ ). The diffraction peaks labeled as "*" are the diffraction peaks from the $\beta$-phase $\mathrm{CsPbl}_{3}$. $\mathbf{d}$, e Scanning electron microscopy (SEM) image of CsPbl 3 perovskite precursor film without and with SCG, respectively, scale bar: $5 \mu \mathrm{m}$. f, $\mathbf{g}$ SEM images of annealed $\mathrm{CsPb}_{3}$ perovskite precursor films without and with SCG, respectively, scale bar: $20 \mu \mathrm{m}$ 
a

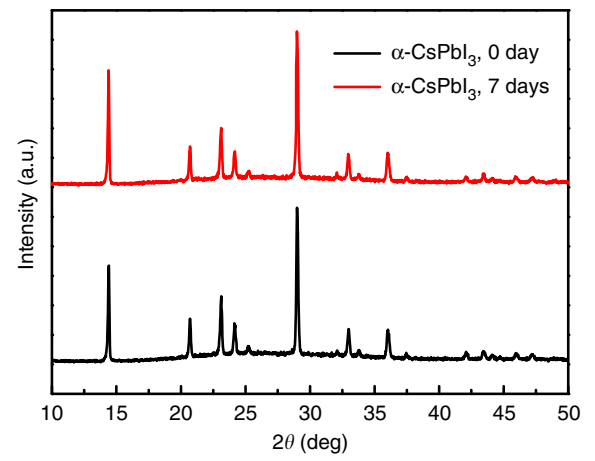

b

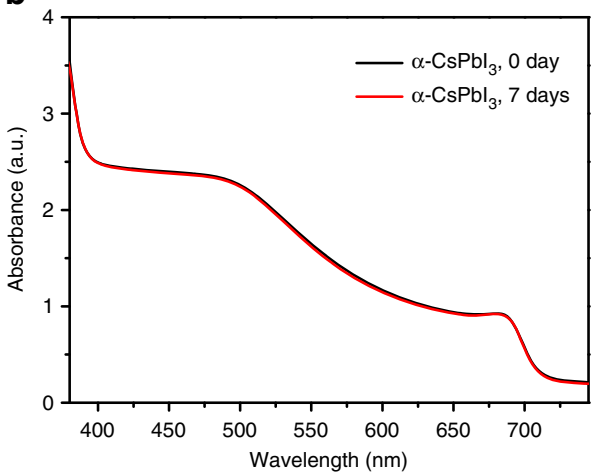

C
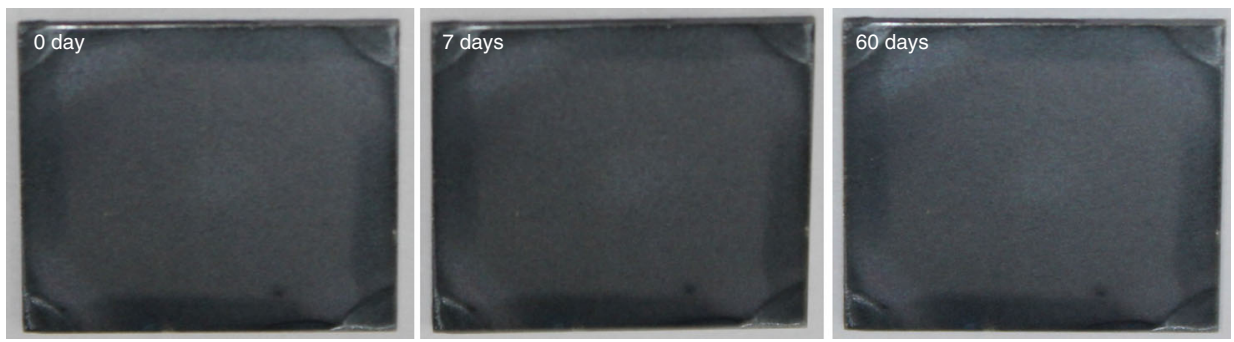

Fig. 2 Phase stability of $\alpha-\mathrm{CsPbl}_{3}$ films in dry nitrogen environment. a X-ray diffraction (XRD) of $\mathrm{CsPbl}_{3}$-precursor films annealed at $350{ }^{\circ} \mathrm{C}$ for 10 min, all the diffraction peaks from the $\alpha$-phase of $\mathrm{CsPb}_{3}$, and also the XRD pattern of $\alpha$ - $\mathrm{CsPb}_{3}$ after storing in a dry nitrogen box for 7 days. $\mathbf{b}$ Absorption of the $\alpha$-phase of $\mathrm{CsPb}_{3}$ films before and after 7 days of storage in dry nitrogen. $\mathbf{c}$ Images of annealed $\mathrm{CsPbl}_{3}$ films stored in dry nitrogen box for different days

cells, the pinholes, and grain boundary in the active layer usually leading to serious recombination and also poor device performance ${ }^{46-48}$.

Herein, we show a simple solvent-controlled growth (SCG) method to produce high-quality $a$-phase $\mathrm{CsPbI}_{3}$ perovskite thin films. To avoid phase transformation of $\mathrm{CsPbI}_{3}$ films, from black to yellow phase triggered by moisture $25,31-33$, we processed the films in dry nitrogen environment, and stable a-phase of $\mathrm{CsPb}_{3}$ was obtained. Adopting the high quality and stable a-phase of $\mathrm{CsPbI}_{3}$ as absorption layer to configure the solar cells, we achieved a PCE of $15.7 \%$ and a certificated PCE of $14.67 \%$, which represent the highest level of inorganic perovskite solar cells so far. More importantly, our preliminary results show that the $\mathrm{CsPbI}_{3}$ solar cells own excellent photostability, the device can tolerate more than $500 \mathrm{~h}$ of continuous light soaking, and no significant efficiency drop is observed.

\section{Results}

Growth of $\mathrm{CsPbI}_{3}$ films. We prepared the $\mathrm{CsPbI}_{3}$-precursor films by spin-coating a solution containing $\mathrm{PbI}_{2}$ and $\mathrm{CsI}$ in a mixture solvent of N,N-dimethylformamide (DMF) and dimethyl sulfoxide (DMSO). It is expected that high boiling point solvent, DMSO $\left(189^{\circ} \mathrm{C}\right)$, could not easily completely escape from the precursor film after spin-coating. The residual DMSO could enhance the mass transport and diffusion, which could improve the film quality if we slow down the evaporation rate of the solvent. Based on this idea, we stand by the precursor films in the nitrogen glove box for several ten minutes before annealing, we named this process as SCG (Fig. 1a).

The spin-coated precursor films without SCG showed greenish-yellow color (inset of Fig. 1b, Supplementary Fig. 1). After SCG, we observed that the color of the precursor films gradually changed from greenish-yellow to light black during SCG (inset of Fig. 1b, Supplementary Fig. 1). As a result, in addition to the absorption edge at $460 \mathrm{~nm}$, an absorption in the visible region was observed, indicating that an additional phase has been formed during SCG. The absorption edge of this additional phase is located at $720 \mathrm{~nm}$, which is similar to $\alpha$-phase $\mathrm{CsPb}_{3}(713 \mathrm{~nm})$ (Figs. $1 \mathrm{~b}$ and $\left.2 \mathrm{~b}\right)$, but with a little red-shift. $\mathrm{X}$-ray diffraction (XRD) results further confirmed the appearance of the additional phase after SCG. For the precursor films without SCG, only the diffraction peaks from the $\delta$-phase $\mathrm{CsPbI}_{3}$ were observed. While for the precursor films with SCG, except for the diffraction peaks from the $\delta$-phase $\mathrm{CsPbI}_{3}$, obvious diffraction peaks located at $14.2^{\circ}, 14.4^{\circ}, 20.2^{\circ}, 28.6^{\circ}$, and $29.0^{\circ}$ were observed. These diffraction peaks could be from $\beta$-phase $\mathrm{CsPbI}_{3}$, which is also a black phase, while owns a slightly distorted crystal structure compared with $\alpha$-phase $\mathrm{CsPbI}_{3}{ }^{49}$ (Figs. 1c and 2a, Supplementary Fig. 2b). Similar $\beta$-phase $\mathrm{CsPbI}_{3}$ has been observed while using phenylethylammonium-stabilized $\mathrm{CsPbI}_{3}$ films ${ }^{49}$. The partial phase change from the $\delta$-phase $\mathrm{CsPbI}_{3}$ to the $\beta$-phase $\mathrm{CsPbI}_{3}$ after SCG indicated that the precursor materials were diffused and the precursor film was reconstructed during solvent evaporation. This enhanced mass transport process could be in favor of the uniform and high-quality film formation.

Accomplished with the formation of an additional phase in the precursor film, we also found that the precursor film became more continuous, and the pinholes in the precursor films have been filled after SCG (Fig. 1d, e). The improvement of morphology also indicated the enhanced diffusion and also the mass transportation during SCG. This will be helpful for obtaining high-quality $a$-phase $\mathrm{CsPbI}_{3}$ perovskite film after annealing. Similar SCG method has been adopted in organic solar cells, while high boiling point solvent such as dichlorobenzene is used, and the enhanced polymer crystallization is observed $^{50}$, while the crystal growth kinetic seems different from the SCG methods shown in this study.

As we expected, the annealed $\mathrm{CsPbI}_{3}$-perovskite films with SCG are free of pinholes and showed crystal size above $5 \mu \mathrm{m}$ (Fig. 1g, Supplementary Fig. 3). However, the $\mathrm{CsPbI}_{3}$-perovskite films obtained without SCG usually showed a large number of 


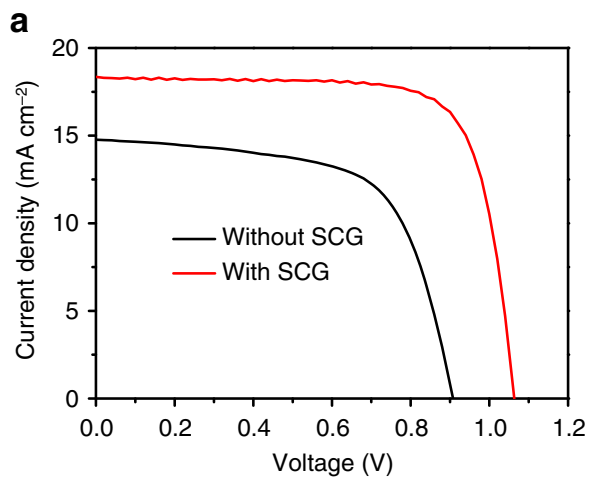

C



b

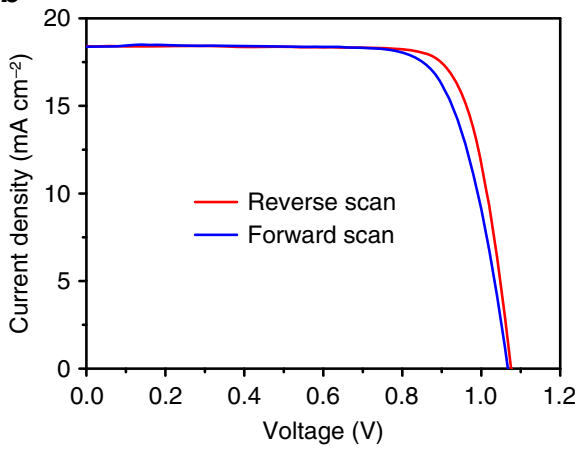

d

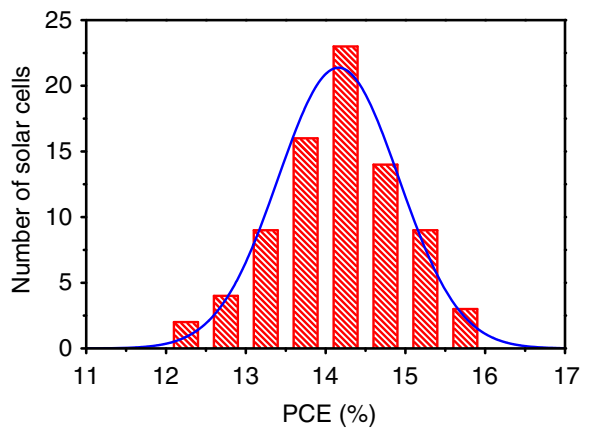

Fig. 3 Device performance of $\mathrm{CsPb}_{3}$-based solar cells. a J-V curves of the devices using $\mathrm{CsPb}_{3}$ as the absorber layer, while the CsPbl 3 without and with solvent-controlled growth (SCG), the SCG time is $50 \mathrm{~min}$. b The device performance under forward scan ( 0 to $1.2 \mathrm{~V})$ and reverse scan ( $1.2 \mathrm{to} 0 \mathrm{~V})$ for the best performance device. $\mathbf{c}$ External quantum efficiency (EQE) spectrum of a $\mathrm{CsPbl}_{3}$ solar cell (black) and the integrated short-circuit current density (red). d Device performance distribution for 80 devices, the curve represents the Gaussian function of the histogram

pinholes (Fig. 1f). The morphology evolution dependent on the SCG times can be found in Supplementary Fig. 4. The significant improvement in perovskite films morphology indicated that SCG process is in favor of obtaining high-quality perovskite films.

Stability of the $\alpha$-phase $\mathrm{CsPbI}_{3}$ film in a dry environment. We carried out the XRD measurement for the annealed $\mathrm{CsPbI}_{3}$ films. We found that a-phase $\mathrm{CsPbI}_{3}$ crystal was formed by two steps from the precursor films with SCG. For the precursor film with SCG, the $\delta$-phase and $\beta$-phase of $\mathrm{CsPbI}_{3}$ coexisted at room temperature, and then was completely changed to $\delta$-phase $\mathrm{CsPbI}_{3}$ after annealing at $150{ }^{\circ} \mathrm{C}$. After that, the precursor film was completely converted into a-phase $\mathrm{CsPbI}_{3}$, while the temperature was increased to $350{ }^{\circ} \mathrm{C}$ (Supplementary Fig. 2a). Encouragingly, we found that the high quality of $\alpha$-phase $\mathrm{CsPbI}_{3}$ that we obtained via SCG method can be maintained in dry nitrogen environment for a long time, and there is no change in the XRD patterns or absorption spectra after 7 days of storage (Fig. 2a, b). And furthermore, the films were not degraded even after more than 2 months of storage in a dry environment (Fig. 2c), indicating that the dry environment can freeze the $\alpha$-phase of $\mathrm{CsPb}_{3}{ }^{25}$. Consistent with the previous reports ${ }^{25}, 34,35$, we also found the induction of phase changes from black to yellowish-white after exposing the films to ambient air with high humidity (Supplementary Fig. 5). Our results showed that the a-phase of $\mathrm{CsPbI}_{3}$ can be maintained at room temperature if we can completely avoid moisture, and additional additives were not needed for phase stabilization $^{25}, 40,41,43-45$. Therefore, we can absolutely achieve stable $\mathrm{CsPbI}_{3}$-based solar cells if we can completely avoid moisture.

Characterizations of $\mathrm{CsPbI}_{3}$ film. We found that the photoluminescence (PL) emission peaks of $\mathrm{CsPbI}_{3}$ were blue-shifted from 710 to $703 \mathrm{~nm}$ after SCG for 50 min (Supplementary Fig. 6), this could be due to the reduction of defect-related traps, while the film quality was improved ${ }^{51}$. We tested the time-resolved photoluminescence (TRPL) of the $\mathrm{CsPbI}_{3}$ films, the lifetime of $\mathrm{CsPbI}_{3}$ was increased from 0.6 to $5.2 \mathrm{~ns}$ after SCG for $50 \mathrm{~min}$ (Supplementary Fig. 6), further confirming that the traps have been reduced after SCG of the perovskite layer. We also found that the $\mathrm{PL}$ of $\mathrm{CsPbI}_{3}$ was improved gradually with increasing SCG time (Supplementary Fig. 6). The lifetime of SCG CsPbI films is in few nanoseconds, which is still shorter than that of organic-inorganic hybrid perovskite with the lifetime in microseconds ${ }^{52,53}$, this could be further improved in future.

We characterized the chemical states and also the band structure of $\mathrm{CsPb}_{3}$ film, the full spectrum of X-ray photoelectron spectroscopy (XPS) and core energy-level spectra confirming the inclusion of $\mathrm{Cs}, \mathrm{Pb}$, and I element (Supplementary Fig. 7). And ultraviolet photoelectron spectroscopy (UPS) measurement was also carried out to determine the band structure of $\mathrm{CsPbI}_{3}$. It could be estimated that the conduction band and valence band of $\mathrm{CsPbI}_{3}$ are about $3.95 \mathrm{eV}$ and $5.68 \mathrm{eV}$, respectively (Supplementary Fig. 8).

CsPbI ${ }_{3}$-based solar cells and device performance. We adopted the high-quality $\mathrm{SCG}-\mathrm{CsPbI}_{3}$ perovskite films as the absorption layer to configure solar cells with the structure of Indium tin oxide (ITO) $/ \mathrm{SnO}_{2} / \mathrm{CsPbI}_{3} /$ Spiro-OMeTAD/Au. N-type of $\mathrm{SnO}_{2}$ was used as the electron transport layer, which was confirmed as an excellent electron transport layer in organic-inorganic perovskite solar cells (Supplementary Fig. 9) ${ }^{10}$, and Spiro-OMeTAD was used as the hole transport layer. A cross-sectional scanning electron microscopy (SEM) image of the completed device is shown in Supplementary Fig. 10. It was found that there is no obvious grain boundary for $\mathrm{CsPbI}_{3}$ in about $3 \mu \mathrm{m}$ scale. From the SEM image, it can be also estimated that the thicknesses of the $\mathrm{SnO}_{2}$, perovskite layer, Spiro-OMeTAD, and Au are about $25 \mathrm{~nm}$, $350 \mathrm{~nm}, 170 \mathrm{~nm}$, and $60 \mathrm{~nm}$, respectively. 
a

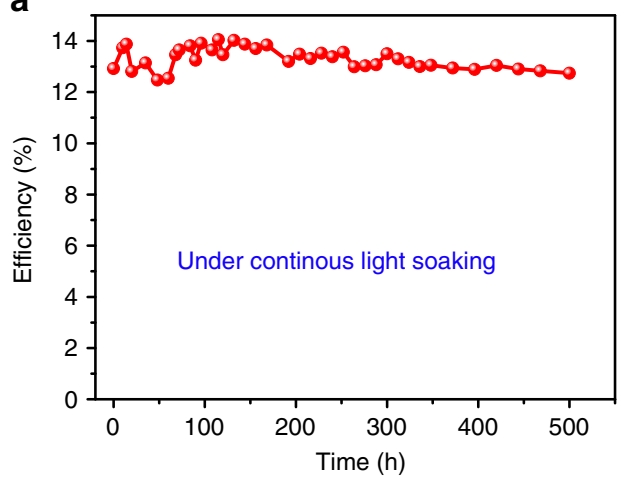

b



Fig. 4 Photostability of the $\mathrm{CsPbl}_{3}$ solar cells. a Photostability measurement of the devices under continuous one-sun illumination (100 mW $\mathrm{cm}^{-2}$ ) with $\mathrm{UV}$ cut filter $(420 \mathrm{~nm})$ in nitrogen glove box (temperature: approximately $25^{\circ} \mathrm{C}$ ) for the unencapsulated devices. $\mathbf{b} \mathrm{J}-\mathrm{V}$ curve of the devices under different continuous light-soaking time

The device performance for the $\mathrm{CsPbI}_{3}$ films with and without SCG was characterized (Fig. 3a, Supplementary Fig. 11). Specifically, when the perovskite layer is without SCG, the devices showed poor performance, with open circuit voltage $\left(V_{\mathrm{OC}}\right)$ of $0.91 \mathrm{~V}$, short-circuit current density $\left(J_{\mathrm{SC}}\right)$ of $14.77 \mathrm{~mA}$ $\mathrm{cm}^{-2}$, fill factor (FF) of $64 \%$, and the efficiency of only $8.58 \%$. The lower performance might be due to too many pinholes in the perovskite layer and lead to serious leakage and recombination ${ }^{46}$. While SCG were carried out, the device performance enhanced significantly (Fig. 3a, Supplementary Fig. 11 and Supplementary Table 1). The best performance of $15.71 \%$ was obtained when the perovskite layer with optimized SCG time for $50 \mathrm{~min}$, with the $V_{\mathrm{OC}}$ of $1.08 \mathrm{~V}, J_{\mathrm{SC}}$ of $18.41 \mathrm{~mA} \mathrm{~cm}^{-2}$, and $\mathrm{FF}$ of $79.32 \%$ (Fig. 3b, reverse scan). The efficiency we achieved here represents a great improvement compared with the previous reports in $\mathrm{CsPbI}_{3}-$ based solar cells (Supplementary Table 2). We tested the device performance under reverse and forward scan, the $J-V$ curves show no appreciable hysteresis between the two different scan directions (Fig. 3b). Reverse and forward scans showed the efficiency of $15.71 \%$ and $14.93 \%$, respectively, the average efficiency is about $15.32 \%$ (Fig. 3b). The typical external quantum efficiency (EQE) of the $\mathrm{CsPbI}_{3}$ solar cells was given (Fig. 3c); the photoresponse edge is about $720 \mathrm{~nm}$, corresponding to the bandgap of $\mathrm{CsPb}_{3}(1.73 \mathrm{eV})$. In the visible region, the EQE can reach up to $85 \%$ with an integrated short-circuit current of 17.7 $\mathrm{mA} \mathrm{cm}{ }^{-2}$, which is almost consistent with the $J-V$ result (Fig. $3 \mathrm{a}$, b). Our devices also showed good reproducibility, the efficiency is located from 12.3 to $15.7 \%$ for 80 devices, and most of the PCEs are about $14 \%$ (Fig. $3 \mathrm{~d}$ ).

We encapsulated the best devices and sent them to photovoltaic calibration laboratory (Newport, an accredited PV calibration laboratory, USA) for certification, which confirmed that a stabilized PCE is $14.67 \%$, the $V_{\mathrm{OC}}$ is $1.097 \mathrm{~V}, J_{\mathrm{SC}}$ is $18.0 \mathrm{~mA}$ $\mathrm{cm}^{-2}$, and $\mathrm{FF}$ is $74 \%$ (Supplementary Figs. 12 and 13). As we know, $\mathrm{CsPbI}_{3}$ is very sensitive to moisture, the certificated results showed that there is no significant degradation during shipping and measurements, while the encapsulated devices were completely exposed to ambient air with moisture for a long time (192 h), inferring that the phase stability issue of $\mathrm{CsPbI}_{3}$ could be completely solved by encapsulation.

Device stability. The stability of perovskite solar cells is a critical issue $^{22,28,54-61}$, we tested the device's stability in the dark and also under continuous light soaking. We found that the device can almost keep its original efficiency when stored in dry nitrogen for $720 \mathrm{~h}$ (30 days) (Supplementary Fig. 14 and Supplementary
Table 3). More importantly, we found that our device showed excellent photostability under continuous light soaking in dry nitrogen environment. After $500 \mathrm{~h}$ of continuous light soaking (AM 1.5G, $100 \mathrm{~mW} \mathrm{~cm}^{-2}$ with $420 \mathrm{~nm}$ UV light filter, temperature: approximately $25^{\circ} \mathrm{C}$ ), the device can maintain its original efficiency and no drop (Fig. 4a). As an example, the initial PCE of the device is $12.97 \%$, after $156 \mathrm{~h}$ of continuous light soaking, the efficiency was slightly increased to $13.7 \%$, which could be due to the improvement of the contact, and then dropped a little to $12.74 \%$ after $500 \mathrm{~h}$ of light soaking (Fig. 4b, Supplementary Table 4). The good photostability of $\mathrm{CsPb}_{3}$ solar cells could be due to the excellent thermal stability or large ion migration barrier of the inorganic perovskite materials ${ }^{37}$. Longertime photostability measurements are also carried out. Further improvement of the $\mathrm{CsPb}_{3}$-solar cells stability could be by doping of the perovskite layer ${ }^{34,43}, 58$, interface engineering $55-57,59,60$, and also advanced encapsulation ${ }^{61}$.

\section{Discussion}

We found that our SCG method could be extended to obtain high-quality $\mathrm{CsPbI}_{2} \mathrm{Br}$ films (Supplementary Fig. 15). According to SCG, a $14.21 \%$ PCE of $\mathrm{CsPbI}_{2} \mathrm{Br}$ solar cells has been obtained (Supplementary Fig. 16 and Supplementary Table 5). Using this SCG method, we have also achieved as high as $16.14 \%$ and $9.81 \%$ PCE of $\mathrm{CsPb}\left(\mathrm{I}_{0.85} \mathrm{Br}_{0.15}\right)_{3^{-}}$and $\mathrm{CsPbBr}_{3}$-based solar cells, respectively (Supplementary Fig. 17). These results indicated that our SCG method is universal at least for high-quality inorganic perovskite films growth and also for obtaining efficient solar cells.

In conclusion, a $15.7 \% \mathrm{PCE}$ of $\mathrm{CsPbI}_{3}$ solar cells have been achieved by SCG of the absorb layer, and the devices can tolerate above $500 \mathrm{~h}$ of continuous light soaking. There is still a large room for device performance, especially on the open-circuit voltage, considering the bandgap of $\mathrm{CsPbI}_{3}(1.73 \mathrm{eV})$; a $1.3 \mathrm{~V}$ open-circuit voltage should be feasible for $\mathrm{CsPbI}_{3}$ solar cells if the contact and the defect can be perfectly controlled, and the efficiency will be close to or beyond $20 \%$.

\section{Methods}

Materials. $\mathrm{SnO}_{2}$-colloid precursor (tin(IV) oxide, $15 \%$ in $\mathrm{H}_{2} \mathrm{O}$ colloidal dispersion), DMF, and DMSO were purchased from Alfa Aesar. CsI and $\mathrm{PbI}_{2}$ were purchased from Sigma Aldrich.

Device fabrication. The ITO-coated transparent conducting substrate was successively washed with detergent solution, distilled water, acetone, and isopropanol, respectively. The $\mathrm{CsPbI}_{3}$-precursor solution is made by dissolving CsI and $\mathrm{PbI}_{2}$ (molar ratio 1:1) in a mixture of DMF and DMSO (v/v, 4:1). A compact 25-nm thin $\mathrm{SnO}_{2}$ layer was spin-coated on the glass/ITO substrates, the details could be found elsewhere ${ }^{10}$. And then, the $0.8 \mathrm{M} \mathrm{CsPbI}_{3}$-precursor solution was deposited by a 
one-step spin-coating process onto the transport layer at the speed of $1500 \mathrm{rpm}$ for $45 \mathrm{~s}$. Other compositions of inorganic perovskite films were also used for fabrication of devices to show that our SCG method is a universal approach. For $\mathrm{CsPbI}_{2} \mathrm{Br}$ solution, $0.8 \mathrm{M}$ CsI mixed with $0.4 \mathrm{M} \mathrm{PbI}_{2}$ and $0.4 \mathrm{M} \mathrm{PbBr}_{2}$ were dissolved in DMF and DMSO solvent. For $\mathrm{CsPb}\left(\mathrm{I}_{0.85} \mathrm{Br}_{0.15}\right)_{3}$ solution, $0.85 \mathrm{M} \mathrm{CsPbI}_{3}$ and $0.15 \mathrm{M} \mathrm{CsPbBr}_{3}$ were mixed. For $\mathrm{CsPbBr}$ solution, $0.4 \mathrm{M}$ of $\mathrm{CsBr}: \mathrm{PbBr}_{2}(1: 1)$ was dissolved in DMF and DMSO solvent. For SCG of the perovskite layer, we dried the fresh spin-coated perovskite precursor films in a glove box, ranging from 0 to $50 \mathrm{~min}$. After drying, the precursor films were annealed at $350^{\circ} \mathrm{C}$ for $10 \mathrm{~min}$ in nitrogen glove box for the formation of $\alpha$-phase $\mathrm{CsPbI}_{3}$ (the annealing temperature of $\mathrm{CsPbBr}_{3}$ is $250^{\circ} \mathrm{C}$ ). For conventional growth without SCG, after spin-coating of perovskite precursor films, annealing was carried out immediately. After cooling of the annealed perovskite films, the Spiro-OMeTAD hole transport layer was applied by spin-coating at $2500 \mathrm{rpm}$ for $30 \mathrm{~s}$. A total of $1 \mathrm{~mL}$ of Spiro-OMeTAD/chlorobenzene solution contained $72.3 \mathrm{mg}$ Spiro-OMeTAD with the addition of $35 \mu \mathrm{L}$ lithium bis(trifluoromethanesulphonyl)imide/acetonitrile $\left(260 \mathrm{mg} \mathrm{mL}^{-1}\right)$ and 30 $\mu \mathrm{L}$ 4-tert-butylpyridine. Eventually, $60 \mathrm{~nm}$ of gold electrode was thermally evaporated on top of the device through a shadow mask, with an effective area of $0.108 \mathrm{~cm}^{2}$.

Characterization. UV-vis spectra were carried out on a Varian Cary $5000 \mathrm{spec}$ trophotometer. SEM measurements were measured with FEI NanoSEM650 to get the relevant parameters, including the morphology and composition of the films, additionally, also includes the device structures. The XRD patterns $(\theta-2 \theta$ scans) were recorded with a Rigaku D/MAX-2500 system operated $\mathrm{Cu} \mathrm{Ka}(\lambda=1.5405 \AA)$ at $40 \mathrm{kV}$ and $200 \mathrm{~mA}$. Steady PL measurement was carried out by Nanolog TCSPC (USA), TRPL were carried out by Edinburgh Instruments F900 (UK). During XRD and PL measurement, to avoid degradation of the films, the films were spin-coated with PMMA for protection, the concentration of the PMMA solution was $8 \%$ in chlorobenzene, and the spin rate was $2000 \mathrm{rpm}$. UPS measurements were conducted on a Thermo Scientific ESCALab 250Xi using HeI $(21.22 \mathrm{eV})$ radiation lines. XPS were also carried out on the Thermo Scientific ESCALab 250Xi with 200 $\mathrm{W}$ monochromated $\mathrm{Al} \mathrm{Ka}(1486.6 \mathrm{eV})$ radiation, and the XPS analysis using a 500 $\mu \mathrm{m}$ X-ray spot. Current-voltage characteristics of the photovoltaic devices were measured with a Keithley 2400 source meter under a simulated AM 1.5G spectrum and a solar simulator (Enli Tech, Taiwan), before each measurement, the solar simulator was calibrated with a Si solar cell (KG-5). The $I-V$ measurements were carried out in nitrogen glove box. The devices are both measured in reverse scan $(1.2$ to $0 \mathrm{~V}$, step $0.02 \mathrm{~V})$ and forward scan $(0$ to $1.2 \mathrm{~V}$, step $0.02 \mathrm{~V})$, the photovoltaic devices were measured in both forward scan and reverse scan at a scan rate of 0.02 $\mathrm{V} \mathrm{s}^{-1}$. The devices were taken out for EQE measurement, the EQE were measured by Enli Tech (Taiwan) EQE measurement system. Devices were encapsulated by the UV-epoxy and use-edge encapsulation method. For our best devices, we encapsulated the devices and then sent to PV calibration laboratory (Newport, an accredited PV calibration laboratory, USA) for certification, and during testing, a metal mask with the size of $0.0738 \mathrm{~cm}^{2}$ has been used. For shelf-stability test, we stored the solar cells in nitrogen glove box and measured it intermittently, and we collected the shelf-stability in $720 \mathrm{~h}$. For the photostability test, the devices were soaked under continuous one-sun condition with UV cut filter (AM 1.5G, $100 \mathrm{~mW}$ $\mathrm{cm}^{-2}, 420 \mathrm{~nm}$ cut filter), the $J-V$ curves were collected every several hours, and we collected the device's photostability in $500 \mathrm{~h}$. The photostability test was also carried out in nitrogen glove box for the device without encapsulation.

Data availability. The data that support the findings of this study are available from the corresponding author upon reasonable request.

Received: 11 February 2018 Accepted: 17 April 2018

Published online: 08 June 2018

\section{References}

1. Kojima, A., Teshima, K., Shirai, Y. \& Miyasaka, T. Organometal halide perovskites as visible-light sensitizers for photovoltaic cells. J. Am. Chem. Soc. 131, 6050-6051 (2009).

2. Kim, H.-S. et al. Lead iodide perovskite sensitized all-solid-state submicron thin film mesoscopic solar cell with efficiency exceeding 9\%. Sci. Rep. 2, 591 (2012).

3. Lee, M. M., Teuscher, J., Miyasaka, T., Murakami, T. N. \& Snaith, H. J. Efficient hybrid solar cells based on meso-superstructured organometal halide perovskites. Science 338, 643-647 (2012).

4. Zhou, H. et al. Interface engineering of highly efficient perovskite solar cells. Science 345, 542-546 (2014).

5. Yang, W. S. et al. High-performance photovoltaic perovskite layers fabricated through intramolecular exchange. Science 348, 1234-1237 (2015).

6. Nie, W. et al. High-efficiency solution-processed perovskite solar cells with millimeter-scale grains. Science 347, 522-525 (2015).
7. Jeon, N. J. et al. Compositional engineering of perovskite materials for highperformance solar cells. Nature 517, 476-480 (2015).

8. Son, D. Y. et al. Self-formed grain boundary healing layer for highly efficient $\mathrm{CH}_{3} \mathrm{NH}_{3} \mathrm{PbI}_{3}$ perovskite solar cells. Nat. Energy 1, 16081 (2016).

9. $\mathrm{Bi}$, D. et al. Polymer-templated nucleation and crystal growth of perovskite films for solar cells with efficiency greater than 21\%. Nat. Energy 1, 16142 (2016).

10. Jiang, Q. et al. Enhanced electron extraction using $\mathrm{SnO}_{2}$ for high-efficiency planar-structure $\mathrm{HC}\left(\mathrm{NH}_{2}\right)_{2} \mathrm{PbI}_{3}$-based perovskite solar cells. Nat. Energy 2, 16177 (2016)

11. Tan, H. et al. Efficient and stable solution-processed planar perovskite solar cells via contact passivation. Science 355, 722-726 (2017).

12. Wu, Y. et al. Perovskite solar cells with $18.21 \%$ efficiency and area over $1 \mathrm{~cm}^{2}$ fabricated by heterojunction engineering. Nat. Energy 1, 16148 (2016).

13. Zheng, $X$. et al. Defect passivation in hybrid perovskite solar cells using quaternary ammonium halide anions and cations. Nat. Energy 2, 17102 (2017).

14. Yang, W. S. et al. Iodide management in formamidinium-lead-halide-based perovskite layers for efficient solar cells. Science 356, 1376-1379 (2017).

15. Chen, H. et al. A solvent- and vacuum-free route to large-area perovskite films for efficient solar modules. Nature 550, 92-95 (2017)

16. Berhe, T. A. et al. Organometal halide perovskite solar cells: degradation and stability. Energy Environ. Sci. 9, 323-356 (2016).

17. Conings, B. et al. Intrinsic thermal instability of methylammonium lead trihalide perovskite. Adv. Energy Mater. 5, 1500477 (2015).

18. Kulbak, M. et al. Cesium enhances long-term stability of lead bromide perovskite-based solar cells. J. Phys. Chem. Lett. 7, 167-172 (2016).

19. Kulbak, M., Cahen, D. \& Hodes, G. How important is the organic part of lead halide perovskite photovoltaic cells? Efficient $\mathrm{Cs} \mathrm{PbBr}_{3}$ cells. J. Phys. Chem. Lett. 6, 2452-2456 (2015).

20. Lee, J. W. et al. Formamidinium and cesium hybridization for photo- and moisture-stable perovskite solar cell. Adv. Energy Mater. 5, 1501310 (2015).

21. Saliba, M. et al. Cesium-containing triple cation perovskite solar cells: improved stability, reproducibility and high efficiency. Energy Environ. Sci. 9, 1989-1997 (2016)

22. Saliba, M. et al. Incorporation of rubidium cations into perovskite solar cells improves photovoltaic performance. Science 354, 206-209 (2016).

23. Li, Z., Yang, M., Park, J.-S., Wei, S.-H., Berry, J. J. \& Zhu, K. Stabilizing perovskite structures by tuning tolerance factor: formation of formamidinium and cesium lead iodide solid-state alloys. Chem. Mater. 28, 284-292 (2016).

24. Eperon, G. E. et al. Formamidinium lead trihalide: a broadly tunable perovskite for efficient planar heterojunction solar cells. Energy Environ. Sci. 7, 982-988 (2014)

25. Eperon, G. E. et al. Inorganic cesium lead iodide perovskite solar cells. J. Mater. Chem. A 3, 19688-19695 (2015).

26. Zhao, D. et al. Low-bandgap mixed tin-lead iodide perovskite absorbers with long carrier lifetimes for all-perovskite tandem solar cells. Nat. Energy 2, 17018 (2017).

27. McMeekin, D. P. et al. A mixed-cation lead mixed-halide perovskite absorber for tandem solar cells. Science 351, 151-155 (2016).

28. Bush, K. A. et al. 23.6\%-efficient monolithic perovskite/silicon tandem solar cells with improved stability. Nat. Energy 2, 17009 (2017).

29. Eperon, G. E. et al. Perovskite-perovskite tandem photovoltaics with optimized bandgaps. Science 354, 861-865 (2016).

30. Ahmad, W., Khan, J., Niu, G. \& Tang, J. Inorganic $\mathrm{CsPbI}_{3}$ perovskite-based solar cells: a choice for a tandem device. Sol. RRL 1, 1700048 (2017).

31. Stoumpos, C. C., Malliakas, C. D. \& Kanatzidis, M. G. Semiconducting tin and lead iodide perovskites with organic cations: phase transitions, high mobilities, and near-infrared photoluminescent properties. Inorg. Chem. 52, 9019-9038 (2013).

32. Dastidar, S. et al. High chloride doping levels stabilize the perovskite phase of cesium lead iodide. Nano Lett. 16, 3563-3570 (2016).

33. Lin, J. et al. Thermochromic halide perovskite solar cells. Nat. Mater. 17, 261-267 (2018)

34. Beal, R. E. et al. Cesium lead halide perovskites with improved stability for tandem solar cells. J. Phys. Chem. Lett. 7, 746-751 (2016).

35. Sutton, R. J. et al. Bandgap-tunable cesium lead halide perovskites with high thermal stability for efficient solar cells. Adv. Energy Mater. 6, 1502458 (2016).

36. Lau, C. F. J. et al. CsPbIBr 2 perovskite solar cell by spray-assisted deposition ACS Energy Lett. 1, 573-577 (2016).

37. Zhou, W. et al. Light-independent ionic transport in inorganic perovskite and ultrastable Cs-based perovskite solar cells. J. Phys. Chem. Lett. 8, 4122-4128 (2017).

38. Frolova, L. A. et al. Highly efficient all-inorganic planar heterojunction perovskite solar cells produced by thermal coevaporation of CsI and $\mathrm{PbI}_{2} . J$. Phys. Chem. Lett. 8, 67-72 (2016).

39. Chen, C. Y. et al. All-vacuum-deposited stoichiometrically balanced inorganic cesium lead halide perovskite solar cells with stabilized efficiency exceeding 11\%. Adv. Mater. 29, 1605290 (2017). 
40. Wang, Q., Zheng, X., Deng, Y., Zhao, J., Chen, Z. \& Huang, J. Stabilizing the $\alpha$-phase of $\mathrm{CsPbI}_{3}$ perovskite by sulfobetaine zwitterions in one-step spincoating films. Joule 1, 1-12 (2017).

41. Luo, P. et al. Solvent engineering for ambient-air-processed, phase-stable $\mathrm{CsPbI}_{3}$ in perovskite solar cells. J. Phys. Chem. Lett. 7, 3603-3608 (2016).

42. Swarnkar, A. et al. Quantum dot-induced phase stabilization of $\mathrm{CsPb}_{3}$ perovskite for high-efficiency photovoltaics. Science 354, 92-95 (2016).

43. $\mathrm{Hu}, \mathrm{Y}$. et al. Bismuth incorporation stabilized $\mathrm{a}-\mathrm{CsPbI}$ for fully inorganic perovskite solar cells. ACS Energy Lett. 2, 2219-2227 (2017).

44. Zhang, T. et al. Bication lead iodide $2 \mathrm{D}$ perovskite component to stabilize inorganic $\alpha-\mathrm{CsPI}_{3}$ perovskite phase for high-efficiency solar cells. Sci. Adv. 3, e1700841 (2017)

45. Sanehira, E. M. et al. Enhanced mobility $\mathrm{CsPbI}_{3}$ quantum dot arrays for record-efficiency, high-voltage photovoltaic cells. Sci. Adv. 3, eaao4204 (2017).

46. Eperon, G. E. et al. Morphological control for high performance, solutionprocessed planar heterojunction perovskite solar cells. Adv. Funct. Mater. 24, 151-157 (2014).

47. Jeon, N. J. et al. Solvent engineering for high-performance inorganic-organic hybrid perovskite solar cells. Nat. Mater. 13, 897-903 (2014).

48. You, J. et al. Moisture assisted perovskite film growth for high performance solar cells. Appl. Phys. Lett. 105, 183902 (2014).

49. Fu, Y. et al. Selective stabilization and photophysical properties of metastable perovskite polymorphs of $\mathrm{CsPbI}_{3}$ in thin films. Chem. Mater. 29, 8385-8394 (2017).

50. Li, G. et al. High-efficiency solution processable polymer photovoltaic cells by self-organization of polymer blends. Nat. Mater. 4, 864-865 (2015).

51. Shao, Y., Xiao, Z., Bi, C., Yuan, Y. \& Huang, J. Origin and elimination of photocurrent hysteresis by fullerene passivation in $\mathrm{CH}_{3} \mathrm{NH}_{3} \mathrm{PbI}_{3}$ planar heterojunction solar cells. Nat. Commun. 5, 5784 (2014).

52. Stranks, S. D. et al. Electron-hole diffusion lengths exceeding 1 micrometer in an organometal trihalide perovskite absorber. Science 342, 341-344 (2013).

53. deQuilettes, D. W. et al. Impact of microstructure on local carrier lifetime in perovskite solar cells. Science 348, 683-686 (2015).

54. Yang, Y. \& You, J. Make perovskite solar cells stable. Nature 544, 155-156 (2017).

55. Mei, A. et al. A hole-conductor-free, fully printable mesoscopic perovskite solar cell with high stability. Science 345, 295-298 (2014).

56. Chen, W. et al. Efficient and stable large-area perovskite solar cells with inorganic charge extraction layers. Science 350, 944-948 (2016)

57. Shin, S. S. et al. Colloidally prepared La-doped $\mathrm{BaSnO}_{3}$ electrodes for efficient, photostable perovskite solar cells. Science 356, 167-171 (2017).

58. Nam, J. K. et al. Potassium incorporation for enhanced performance and stability of fully inorganic cesium lead halide perovskite solar cells. Nano Lett. 17, 2028-2033 (2017).

59. Arora, N. et al. Perovskite solar cells with CuSCN hole extraction layers yield stabilized efficiencies greater than 20\%. Science 358, 768-771 (2017).

60. Hou, Y. et al. A generic interface to reduce the efficiency-stability-cost gap of perovskite solar cells. Science 358, 1192-1197 (2017).
61. Bella, F. et al. Improving efficiency and stability of perovskite solar cells with photocurable fluoropolymers. Science 354, 203-206 (2016).

\section{Acknowledgments}

This work was supported by National Key Research and Development Program of China (Grant No. 2016YFB0700700), National Natural Science Foundation of China (Grant Numbers: 61634001, 61574133), Beijing Municipal Science \& Technology Commission (Grant No. Z181100004718005), National 1000 Young Talents awards and also was partially supported by Hanergy group.

\section{Author contributions}

J.Y. conceived the idea, directed, and supervised the project. P.W. fabricated the devices and collected all the data. X.Z., Y.Z., Q.J., Q.Y., X.L., X.Y., Z.C., and Z.Y. were involved in data analysis. J.Y. and P.W. co-wrote the manuscript. All authors contributed to the discussions and finalizing of the manuscript.

\section{Additional information}

Supplementary Information accompanies this paper at https://doi.org/10.1038/s41467018-04636-4.

Competing interests: The authors declare no competing interests.

Reprints and permission information is available online at http://npg.nature.com/ reprintsandpermissions/

Publisher's note: Springer Nature remains neutral with regard to jurisdictional claims in published maps and institutional affiliations.

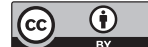

Open Access This article is licensed under a Creative Commons Attribution 4.0 International License, which permits use, sharing, adaptation, distribution and reproduction in any medium or format, as long as you give appropriate credit to the original author(s) and the source, provide a link to the Creative Commons license, and indicate if changes were made. The images or other third party material in this article are included in the article's Creative Commons license, unless indicated otherwise in a credit line to the material. If material is not included in the article's Creative Commons license and your intended use is not permitted by statutory regulation or exceeds the permitted use, you will need to obtain permission directly from the copyright holder. To view a copy of this license, visit http://creativecommons.org/ licenses/by/4.0/.

(C) The Author(s) 2018 